\title{
Normative learning and employee cognitive engagement in selected pharmaceutical firms in Nigeria
}

\author{
O. Opeyemi, C. Moses, E. Igbinoba, O. Salau, M. Olokundun, T. Atolagbe \\ Department of Business Management, Covenant University, Ota \\ Nigeria \\ Received: February 26, 2020. Revised: August 30, 2020. 2nd Revised: November 13, 2020. \\ Accepted: November 20, 2020. Published: November 23, 2020.
}

\begin{abstract}
This study examined the effect of normative learning on employee cognitive engagement. Survey research design was adopted to assess the subject matter. Five hundred and forty-one hundred (541) respondents were surveyed across all the selected pharmaceutical companies in Nigeria with the usage of purposive and stratified sampling technique. Only four hundred and thirty-four (434) copies of questionnaire representing $(\mathbf{8 0 . 2 \%})$ response rate was correctly filled, returned and analysed for this study. Structural Equation Model (AMOS 23) was adopted for the analysis of the effect of normative learning on employee cognitive engagement and efficacy of employee engagement to work and job task. The results from the test of hypotheses showed that normative learning significantly influence employee cognitive engagement $\left(R^{2}=0.840\right.$ p-value $\left.=0.000\right)$. The study recommends that management of the selected firms should develop functional systems that ensure transfer of best practices among various areas of work and encourage individual members in teams to have clear understanding of the problem to be addressed. The insights from this study would be of great value to the management of pharmaceutical industry, and other stakeholders to develop and invest in normative learning that will enhance job commitment and engagement of employees.
\end{abstract}

Keywords-Employee cognitive engagement, job commitment, normative learning.

\section{INTRODUCTION}

$\mathrm{T}$ HE pharmaceutical industry plays an important role in fostering the health and well-being of the citizens of any nation. Therefore, it is pertinent to give attention to issues and concerns of the industry. Pharmaceutical industry is an important social and economic asset for human development. Three of the seventeen sustainable development goals SDGs call for specific health improvements by 2030 which are to ensure good health and promote well-being at all cost, infrastructure and industry innovation (SDG 3 \& 9), and responsible consumption and production (SDG 12). Pharmaceutical industry is also increasingly viewed as important to the achievement of other SDGs, including eradicating extreme poverty and hunger (SDG $1 \& 2$ ), and promoting quality education (MDG 4). [1], [2] acclaimed that for the SDGs to be achieved and sustained, the industry requires the services of employees with the required skill sets that concentrate and gets engrossed in work while carrying out their roles. Engaged employees apply themselves totally (body, soul and emotion) to their assigned roles and they have positive attitudes towards the organization and its values.

Employee engagement in the pharmaceutical industry across the globe is a major driver of competitive advantage and has gained popularity over the years [3]. According to [4], engaged employees are aware of the business environment and work cordially with colleagues to improve job output for the industry's benefit. Pharmaceutical industry must in turn nurture and develop engagement which is a two-way relationship between employee and employer. Employee engagement positively impacts on the employees and the industry. On the part of employees, it provides the opportunity to contribute to operational activities of the industry which engenders a sense of value and belonging. Employees tend to be dedicated to the industry's developmental activities acquiring knowledge, through thoughts, experiences and senses (cognitive engagement). This is why it is organizational learning is a pertinent issue especially in respect to firms in the pharmaceutical industry who are prone to innovations.

Organizational learning is the firm's capacity to acquire, utilize, and share information that would enable them achieve control in the global market place and could be at the individual, group and organisational level although learning can start at the individual level [5], [6]. Organisational learning in this context comprises, normative learning which implies learning on individual (personal mastery, mental modeling), collective (shared visioning, team-learning) and organizational (systems thinking) level. Normative learning in the pharmaceutical industry leads to technological innovation, product enhancement and process improvement. It can also lead to increased level of organisational competitiveness which is the panacea for long term organisational growth and success. It has been established that the degree of organisational turbulence is positively linked to organisational learning [7]. This implies that the higher the change that occur in the pharmaceutical industry's business environment, the higher the 
need for normative learning especially in developing country such as Nigeria [8].

Nigeria, as a country possesses large human capital and natural resources yet troubled with brain drain, dissatisfaction and lack of innovation particularly in the health sector. High disease incidence in the country has called for great attention particularly because of her position in Africa as the most populous country with the largest and fast growing economy [8]. These have posed a great challenge especially to pharmaceutical industry in the country. There is a likelihood that organisational learning can foster employee engagement in the Nigerian pharmaceutical industry, this is consequent upon the fact that employees' get focused and mentally alert to think through what they have learnt which stimulates them to engage with task creatively. Based on this background this study will examine the relationship between organisational learning and employee engagement and in the Nigerian pharmaceutical industry.

\section{Statement Of The Research Problem}

World invasion with terminal diseases and health related issues requires new discoveries. These volatility, uncertainty and turbulence of the business environment is prevalent in Nigeria especially in the Pharmaceutical industry because of the peculiarity of their business activities. The pharmaceutical industry is saddled with responsibility of discovering innovative ways of solving health challenges within its environment.

Normative learning includes shared visioning and team building and this enhances employee cognitive engagement in the sense that employees are able to engage in productive tasks with purposiveness while also making cognitive investment in learning. This also implies that employees are able to devote full attention to their work [9]. However, trends in the pharmaceutical industry reveal that as a consequence of the workload from dealing with ailing patients and managing team work, employees' experience huge stress and burnout [10]. [11], reveal that $30 \%$ of Nigerian pharmacist's experience burn out, frustration and exhaustion in the workplace. To this end, extant studies such as [12], [13] examined the relationship between normative learning and employee job satisfaction in the manufacturing industry. In the same vein, [14], [2] examined the relationship between organizational learning and employee motivation. Nevertheless, these studies have not explained how normative learning can be used to facilitate cognitive engagement of employees particularly in the Nigerian pharmaceutical industry.

\section{Research Hypotheses}

$\mathbf{H}_{01}$ : There is no significant effect of normative learning on cognitive engagement of employees.

\section{LITERATURE REVIEW}

\section{A. The concept of learning}

Learning is a formal and deliberate development that continue throughout life. Learning is the way to understand one-self as well as others. Learning also provides the opportunity for individual's self-discovery and understanding [15]. Learning takes place in different ways which implies skills or information can be communicated implicitly or learnt incidentally. The process of learning actually starts from feedback and response from others [15]. Learning allows organizational members to achieve their personal goals, flexible thinking, drawing on past knowledge, persistence, empathic listening, checking for accuracy, decreased impulsivity, cooperative thinking, meta cognition, build satisfying and fruitful bond with others and also experience the challenges that make life meaningful [16].

\section{B. Organizational learning}

Organizational learning is the capacity of an organization to acquire, utilize, and share information that would enable them achieve control in the global market place. Organizational learning take place when a unit in an organization acquires information that is recognized as potentially useful to the organization [16]. Organizational learning concept was first introduced in the literature by Kurt and March in 1963 [6]. While [17], were the first to introduce it with empirical analysis. Organizational learning emphasizes a well-designed process that allows for continuous improvement on working capabilities, dexterity of ideas and information crossfertilization as shared between individuals in the organization. Organizational learning according to [18], is the direct product of organizational inquiry. However, the presence of organizational inquiry in organizations makes employees to interact with cognoscente's individuals with cognate experience on the operation management through which they acquire information. [19], agreed with this assumption as they argued that organizational learning is a direct outcome of interaction with individuals who have acquired operational skills in the organization.

\section{Normative learning}

The normative learning explains how organizations learn and brings themselves close to the ideals. Normative learning tends to ask questions on how to improve learning and explains what is involved in making learning a reality with proofs. It is sometimes referred to as a learning organization, which is multidimensional and complex in approach. The discipline of normative learning has been able to combine learning on individual (personal mastery, mental modeling), collective (shared visioning, team-learning) and organizational (systems thinking) level.

Personal Mastery: Personal mastery explains learning at the individual level. Individual that practice personal mastery end up experiencing changes in their thinking. They have learnt to use their reasoning and intuition [20]. Employee learns to expand personal mastery by understanding their dreams and capacities. This also entails the discipline of self-development, learning and personal growth. Employees that have personal mastery later become systems thinkers that see 
interconnectivity of everything in the organization. Individual commitment to the learning process is called personal mastery. However, personal mastery cannot be forced on individuals especially those that are receptive to learning and resist change [20].

Shared Vision: A vision is a lifelike, graphic mental image that we held important to us, within our hearts [21]. A shared vision in organizations also begins with the individual. This implies that the organization's shared vision is also built on the individual member's vision in the organization. Shared vision motivates employees to learn, because it leads to common identity that provides energy and direction for learning. Consequently, shared vision creation can be affected by organizational traditional structures especially where visions are imposed from the leaders. Therefore, organizations' learning happens easier and faster with decentralized and flat organizational structures.

Mental Models: Mental models are framework for the cognitive processes of our mind. Mental models are also the assumption held by the individuals and organizations. Mental model determines how we think and act in the organization [21]. As a result, pharmaceutical firms must ensure that before learning takes place individual mental models are challenged. Therefore, to learn and achieve high performance in the firm people must come together and talk about how they feel about the organization's goals, and the how their day-to-day tasks can lead to the accomplishment of the mission and goals.

Team Building: A team comprises of group of people (usually lesser than twenty) with complementary skills and is committed to the performance of specific goals. The group members develop collective thinking skills and the collaboration process of working together to develop knowledge efficiently. Organizational team members can come together to achieve the purpose and goals of the team [22]. In order to achieve effective teams in the pharmaceutical industry every member must be committed to continual improvement and learning. Every member of the team must be given the opportunity to discover drug and its development, innovate, co-create, improve services, and ensure the smooth running of the organization. The team approach to drug discovery and development differs from the stereotype of an academic scientist working independently on his or her own project.

Systems Thinking: This is a framework for seeing patterns and interrelationships in the organization. Systems explain how parts are interacting and dependent upon each other and not what each part does alone. Organizational learning actively facilitates rewards and promotes collective learning. Systematic thinking organizations knows the world is full of overwhelming complexities and accelerated change and therefore impact positively by actively capturing, transferring, mobilizing and creating knowledge to allow them have competitive advantage in the changing world [23]. Organisations will as a result acclimatize and constantly improve which in turn positively affects their employee engagement. Learning organisation sees the world as a whole as it grows more and more complex [9]. This enables them to act in tune with the larger process of the natural economic world seeing wholes instead of parts, processes rather than events and dynamic rather than detail complexity.

\section{Employee engagement}

Employee engagement is the degree at which employees are engrossed and concentrate in work while carrying out their roles [24]. Engagement is also how employee gets involved and dedicated in work. According to [25], workers are more engaged when they feel there is meaningful and safe work to be done. Employee engagement is behavioral and cognitive in nature.

Behavioral Engagement: Behavioral engagement is the display of behaviors and work beyond the terms of contract by employees. This is the ability for employees to go extra mile to get work done for their organization [24]. It involves the ability for employees to engage physically to their work. Behavioral engagement is often heightened when employees take care of themselves physically and medically with thoughts of how not to be a liability to the organization in the present and future.

Cognitive Engagement: Cognitive engagement is defined as the degree at which employees are mentally alert to their jobs roles with the goal of the organization in their mind [26]. An employee is said to be cognitively engaged when he has an enduring, fulfilling and positive attitude that makes him focused and psychologically present in organizational job activities [27], [28]. Studies such as [11], [6] reveals that organizations with efficient and effective information distribution experience a high level of employee cognitive engagement.

\section{Methodology}

The main objective of this research is to examine the effect of normative learning on employee cognitive engagement. Descriptive research design was employed for this study which provides a clear, detailed and vivid description of situation without any form of manipulation. In other to harmonize and analyze the data, SPSS and AMOS 23 (SEM) was employed to examine the degree of goodness-of-fit and the influence of normative learning on employee cognitive engagement. Meanwhile, factor model was carried out to show the level of reliability while the degree of fitness was revealed and construct validity was carried out through discriminant and convergent analyses.

The study population comprises 6 pharmaceutical companies that were regarded as 'the best' in terms of scientific research, innovativeness and quality [29]. These companies were selected based on the fact that they export pharmaceutical products to Ecowas countries [30]. The innovative culture of these companies that fosters export is considered a function of corporate learning and engagement. Due to the large number of employee in the selected pharmaceutical companies, administering questionnaire to them all becomes extremely difficulty, therefore, a sample of 
541 respondents was chosen. The sample size was arrived at using [31] sample size determination table as cited in [32]. The multiple sampling techniques which include purposeful stratified and convenience sampling techniques were adopted for the study. Purposeful sampling was used because only the employee of the selected pharmaceutical companies was considered in the survey. Stratified sampling was also adopted because the population is made up of different strata and within each stratum, every employee was given equal opportunity of been selected.

Structured questionnaire specifically 5-point Likert scale was used to obtain data based on the literature reviewed on the subject matter. This helps to know the level of participant's agreement with items in the instrument. In order to ensure that presented data are adequate and precise, the measures for the assumptions of analysis as suggested by [33] were carefully followed. Thus, the acceptance values and variance inflation factor values were within the threshold $>0.2$ and $>5.0$ respectively. The normality and linearity were analyzed and 107 respondents from the original sample of 541 were removed using Mahalanobis Distance Criterion. Listwise deletion method was used to eliminate missing data which was less than 5 percent. The final sample for the study was four hundred and thirty-four (434) representing (80.2\%) of respondents which is considered to be accurate. The reliability, unidimensionality and validity were assessed after the amendment of the final measurement model. The reliability was carried out using CFA loading, construct composite reliability, error variance, construct average variance extracted estimate. CFA loading, and construct composite reliability are within the minimum benchmark of 0.70 and 0.80 respectively. In addition, error variance should be less than 0.5 while construct average variance extracted estimate should be above 0.5. The outcome of CFA with the specific indices is presented in Table 1.

\section{RESULT}

Table 1 shows the measurement legend. Normative learning was measured with eight (8) items in the research instrument represented as NL1.............. NL8 while the cognitive engagement was measured with eight (5) items represented as CE1........CE5. Based on the criteria set by some scholars as enumerated under interpretation of measurement model, all scale and measurement items are above the minimum threshold value of 0.70 ; every construct composite reliability surpasses 0.80 , each of the construct average variance extracted estimate (AVE) is above the minimum threshold of 0.50 while Cronbach Alpha is also above 0.70.in a related development, the output of CFA analysis indicates that the factor loadings for the specific measures of construct ranged between 0.816 and 0.912 . The instrument is adjudged reliable and valid since all the criteria for the degree of fitness were met.

Table I Factor loading of the effect of normative learning on employee cognitive engagement

\begin{tabular}{|c|c|c|c|c|c|c|c|}
\hline & $\begin{array}{c}\text { Std. } \\
\text { Loading }\end{array}$ & $\begin{array}{l}\text { Indicator } \\
\text { Reliability }\end{array}$ & $\begin{array}{c}\text { Error } \\
\text { Variance }\end{array}$ & $\begin{array}{l}\text { Composite } \\
\text { Reliability }\end{array}$ & AVE & $\begin{array}{c}\text { Cronbach's } \\
\text { Alpha }\end{array}$ & $\begin{array}{c}\text { No. of } \\
\text { Indicators }\end{array}$ \\
\hline Indicators & $>0.7$ & & $<0.5$ & $\geq 0.8$ & $\geq 0.5$ & $\geq 0.7$ & \\
\hline \multicolumn{4}{|c|}{ Normative Learning (NL) } & 0.96666 & 0.7838 & 0.984 & 8 \\
\hline NL1 & 1) 0.912 & 0.8317 & 0.1683 & & & & \\
\hline NL2 & 2) 0.877 & 0.7691 & 0.2309 & & & & \\
\hline NL3 & 3) 0.888 & 0.7885 & 0.2115 & & & & \\
\hline NL4 & 4) 0.891 & 0.7939 & 0.2061 & & & & \\
\hline NL5 & 5) 0.883 & 0.7797 & 0.2203 & & & & \\
\hline NL6 & 6) 0.876 & 0.7674 & 0.2326 & & & & \\
\hline NL7 & 7) 0.877 & 0.7691 & 0.2309 & & & & \\
\hline NL8 & 8) 0.878 & 0.7709 & 0.2291 & & & & \\
\hline \multicolumn{4}{|c|}{ Cognitive Engagement (CE) } & 0.93371 & 0.7788 & 0.875 & 5 \\
\hline CE1 & 9) 0.901 & 0.8118 & 0.1882 & & & & \\
\hline CE2 & 10) 0.877 & 0.7691 & 0.2309 & & & & \\
\hline CE3 & 11) 0.889 & 0.7903 & 0.2097 & & & & \\
\hline CE4 & 12) 0.881 & 0.7762 & 0.2238 & & & & \\
\hline CE5 & 13) 0.883 & 0.7797 & 0.2203 & & & & \\
\hline
\end{tabular}

\section{H01: There is no significant effect of normative learning} on cognitive engagement of employees.

Fig. 1 portrays the structural equation modeling of the effect of normative learning on cognitive engagement with standardized estimates. The normative leaning which is the latent variable was measured with eight (8) items while cognitive engagement which is the observed variable was measured with five (5) items. It must be reported that factor loading as shown in Table I for all the items were above the minimum threshold of 0.50 and as well statistically significant at 0.05 level of significance as suggested by [33]. 


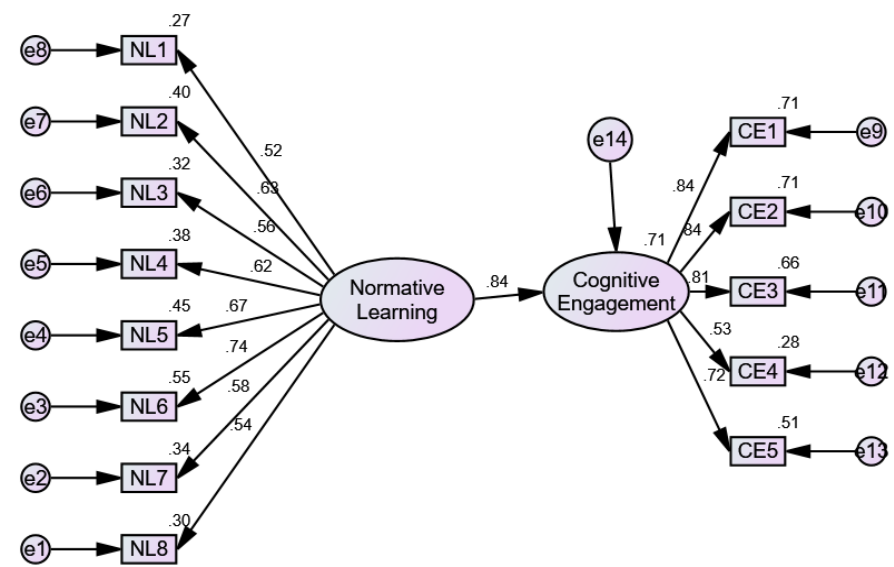

Fig. 1 Structural equation modeling for Hypothesis 1

The structural path coefficient $(\mathrm{NL} \rightarrow \mathrm{CE})$ for standardized and unstandardized model accounted for 0.840 and 1.311 respectively as depicted in Table II and Fig. 1. It should be noted that structural path coefficient is also known as Coefficient of Determination $\left(\mathrm{R}^{2}\right)$ that is used as criteria for assessing structural model as well as the predictive validity power of the model [34]. However, going by the $\mathrm{R}^{2}$ value of standardized model which is $84 \%$, it suggests an acceptable level of prediction for empirical study because it greatly accounts for the variation of the proposed model.

Table 2 Maximum likelihood estimates of normative learning and cognitive engagement

\begin{tabular}{|c|c|c|c|c|c|c|c|}
\hline & & & $\begin{array}{l}\text { Unstandar } \\
\text { dized } \\
\text { Estimate }\end{array}$ & $\begin{array}{l}\text { Standar } \\
\text { dized } \\
\text { Estimate }\end{array}$ & S.E. & C.R. & $\mathrm{P}$ \\
\hline \multicolumn{8}{|c|}{ Structural Path } \\
\hline$\overline{\mathrm{CE}}$ & $<---$ & NL & 1.311 & .840 & .122 & 10.785 & $* * *$ \\
\hline \multicolumn{8}{|c|}{ Measurement } \\
\hline NL8 & $<---$ & NL & 1.000 & .544 & .089 & 8.826 & $* * *$ \\
\hline NL7 & $<---$ & NL & .917 & .583 & .101 & 9.082 & $* * *$ \\
\hline NL6 & $<---$ & NL & 1.253 & .743 & .120 & 10.460 & $* * *$ \\
\hline NL5 & $<---$ & NL & 1.068 & .671 & .106 & 10.058 & $* * *$ \\
\hline NL4 & $<---$ & NL & .950 & .617 & .101 & 9.379 & $* * *$ \\
\hline NL3 & $<---$ & NL & .689 & .564 & .079 & 8.724 & $* * *$ \\
\hline NL2 & $<---$ & NL & .943 & .634 & .099 & 9.520 & $* * *$ \\
\hline NL1 & $<---$ & NL & .773 & .517 & .091 & 8.537 & $* * *$ \\
\hline CE1 & $<---$ & $\mathrm{CE}$ & 1.000 & .845 & .055 & 21.864 & $* * *$ \\
\hline CE2 & $<---$ & $\mathrm{CE}$ & .935 & .843 & .045 & 20.812 & $* * *$ \\
\hline CE3 & $<---$ & $\mathrm{CE}$ & .915 & .814 & .046 & 19.956 & $* * *$ \\
\hline CE4 & $<---$ & $\mathrm{CE}$ & .562 & .529 & .050 & 11.189 & $* * *$ \\
\hline CE5 & $<---$ & $\mathrm{CE}$ & .843 & .716 & .050 & 16.752 & $* * *$ \\
\hline
\end{tabular}

Table III Goodness of fit statistics for objective 2

\begin{tabular}{lllllllll}
\hline Model & $\mathbf{X}^{\mathbf{2}} / \mathbf{D F}$ & P-value & IFI & NFI & CFI & GFI & AGFI & RMSEA \\
\hline Parameters Recommended & $<3.0$ & $<0.05$ & $>0.9$ & $>0.9$ & $>0.9$ & $>0.8$ & $>0.8$ & $<0.08$ \\
Goodness of Fit & 7.939 & 0.000 & 0.935 & 0.915 & 0.934 & 0.951 & 0.888 & 0.025 \\
\hline
\end{tabular}

Table III shows various forms of Goodness-of-fit indicators in assessing specified model of the study. This shows that the constructs fits the data agreeing to the complete, incremental, and mean model fit measures, comprising chi-square per degree of freedom ratio $\left(\mathrm{x}^{2} / \mathrm{df}\right)$ and other indicators presented in Table III. However, Table III also depicts the outcomes of the Goodness-of-fit of various indicators, the findings show that the formulated hypothesis as shown in the model greatly fit the sample data. This suggests that the predictive capability of employee cognitive engagement on normative learning is statistically significant as presented in Table III.

Note: $\mathrm{X} 2 / \mathrm{DF}=$ Chi-square/degree of freedom, P-value= Significant, IFI= Incremental Fix Index, NFI = Normed Fit Index $\mathrm{CFI}=$ Comparative Fit Index GFI $=$ Goodness-of-Fit Index, AGFI= Adjusted Goodness of fit and RMSEA = Root Mean Square Error of Approximation

\section{CONCLUSION}

This study concludes that normative learning which includes personal mastery, shared visioning, mental models, team building and systematic thinking has positive influence on employee cognitive engagement because employees are able to engage in productive tasks with purposiveness while also making cognitive investment in learning. This implies that normative learning stimulates employees' in getting focused and mentally alert to think through what they have learnt thereby achieving organisational productivity and success.

\section{RECOMMENDATIONS}

This study recommends that management of the selected firms should develop functional systems that ensure transfer of best practices among various areas of work (e.g. mentoring), encourage individual members in teams to have clear understanding of the problem to be addressed and also explicitly reward employees that are a source of quality information.

There is also a great need for the firms to reliably encourage employees to use their skills and capabilities in the work process and satisfaction of customers 'expectations.

\section{References}

[1] O. Inegbenojie, "Manpower Training and Development and Deposit Money Bank Performance in Nigeria. An MBA Thesis Submitted to the Postgraduate School, Federal University of Technology, Owerri, 2018.

[2] R. Savolainen, "Information Distribution and Knowledge Sharing as Communicative Activities. Information Research," vol. 22, pp. 17-30, 2017. 
[3] E. Edmonstone, "Organisational learning. Leadership in Health Services," vol. 31, 434-440, 2018.

[4] U. Agbionu, M. Anyalor, and A. Nwali, "Employee Engagement and Performance of Lecturers in Nigerian Tertiary Institutions," Journal of Education \& Entrepreneurship, vol. 5, pp. 69- 87, 2018.

[5] O. Ogueyungbo, C. Moses, and E. Igbinoba, "Organisational learning and employee engagement: A literature review. 5th International Conference on Advances in Education and Social Sciences held in Istanbul," 2019.

[6] H. Odor, and P. Samuel, "Organisational Learning and Learning organisation: A Literature Review," European Journal of Business and Management, vol. 10, pp. 2222$1905,2018$.

[7] R. Chiva, and J. Habib, "A Framework for Organisational Learning: Zero, Adaptive and Generative Learning," Journal of Management and Organisation, vol. 21, pp. 119, 2018.

[8] Y. Oseni, "Pharmacists' Distribution in Nigeria, Implication in the Provision of Safe Medicines and Pharmaceutical Care," International Journal of Pharmacy and Pharmaceutical Sciences, vol. 9, pp. 7-10.

[9] P. Senge, "The fifth discipline: The Art \& Practice of the Learning Organisation," New York: Doubleday Business, 1990.

[10]M. Ikon, and C. Chika, "Employee Engagement and Performance of Selected Private Universities in Delta state, Nigeria," Global Journal of Human Resources Management, vol. 5, pp. 42-53, 2017.

[11]E. Aguwa, I. Nduka, and S. Arinze-Onyia, "Assessment of Burnout among Health Workers and Bankers in Aba South Local Government Area, Abia state, South East Nigeria," Nigeria Journal of Clinical Practice, vol. 17, pp. 296-302, 2017.

[12] O. Chiekezie, L. Onwuzuligbo, O. Orogbu, and T. Okafor, "Employee Engagement and Performance in Selected Ministries in Anambra State Civil Service of Nigeria," Journal of Economics and Public Finance, vol. 2, pp. 1720, 2016.

[13]H. Mohajan, "Knowledge Sharing Enhances Knowledge Management Environment and Efficiency. Journal of Environmental Treatment Techniques, vol. 5, pp. 78-82, 2017.

[14] S. Abolarinwa, "Organisation Trust, Affectivity, Knowledge Acquisition, as factor Affecting Organisational Learning of Managers," International Journal of Information Research and Review, vol. 3, pp. 1625-1629, 2016.

[15]M. Yasar, A. Ahmed, and A. Emhan, "Analysis of relationships between Organisational Learning Capacity and Organisational Performance: A case study of Banking Sector in Nigeria," Arabian Journal of Business and Management Review (Nigerian Chapter), vol. 2, pp. 2022, 2014.

[16]E. Hartonoa, S. Wahyudi, P. Harahap, and A. Yuniawan, "Does Organisational Learning affect the Performance of Higher Education Lecturers in Indonesia? The Mediating
Role of Teaching Competence," International Journal of Environmental and Science Education, vol. 12, pp. 865878, 2017.

[17] V. Cangelosi, and W. Dill, "Organisational Learning: Observations toward a theory," Administrative Science Quarterly, vol. 10, pp. 175-203, 1965.

[18]E. Chukwuma, O. Godwin, and O. Ndidi, "Organisational Learning and Performance of Selected Paint Manufacturing Firms in Lagos State, Nigeria," International Journal of Investment Management and Financial Innovations, vol. 3, pp. 44-50, 2017.

[19] J. Gilley, and A. Maybunich, "Beyond the Learning Organisation, Creating a Culture of Continuous Growth and Development through State-of- the-Art Human Resource Practices, Cambridge," Mass: Perseus Books, 2016.

[20]S. Yadav, and V. Agarwal, "Benefits and Barriers of Learning Organisation," Journal of Applied Statistics, vol. 10, pp. 18-22, 2016.

[21]O. Ogueyungbo, C. Moses, and E. Igbinoba, The Relationship between Information Interpretation and Employee Affective Engagement: A Literature Review. 5th International Conference on Advances in Education and Social Sciences held in Istanbul, 2019.

[22]H. Nutley, and S. Davies, "Facing the Challenges of Research- Informed Knowledge Mobilization: 'Practicing What We Preach'," Annual Review of Sociology, vol. 96, pp. 36-52, 2018.

[23]A. Ramírez, V. Morale, and R. Rojas, Knowledge Creation, Organisational Learning and their Effects on Organisational Performance," International Journal of Production Economics, vol. 133, pp. 66-70, 2011.

[24]A. Saks, "What do we really know about Employee engagement," Human Resource Development Quarterly, vol. 25, pp.155-182, 2016.

[25]A. Kahn, "Psychological Conditions of Personal engagement and disengagement at work," Academy of Management Journal, vol. 33, pp. 692-724, 1990.

[26]B. Bakker, and E. Demerouti, "Towards a model of work engagement," Career Development International, vol. 13, pp. 209-223, 2018.

[27]M. Ikon, and C. Chika, "Employee Engagement and Performance of Selected Private Universities in Delta state, Nigeria. Global Journal of Human Resources Management, vol. 5, pp. 42-53, 2018.

[28] O. Salau, A. Osibanjo, A. Adeniji, E. Igbinoba, and O. Ogueyungbo, " Data Regarding Talent Management Practices and Innovation Performance of Academic Staff in a Technology-Driven Private University," Data in Brief, vol. 19, pp. 1040-1045.

[29] Pharmaceutical Manufacturing Group of Manufacturers' "Association of Nigeria, Report on the status of Nigerian pharmaceutical industry. Pharmaceutical Manufacturing Group of Manufacturers' Association of Nigeria, Lagos," 2019.

[30]C. Bratianu, "Organisational Knowledge Dynamics: Managing Knowledge Creation, Acquisition, Sharing, and Transformation," Hershey: IGI Global, 2018. 
[31] J. Gill, P. Johnson, and P. Clark, "Research Methods for Managers," Journal of Business and Economics, vol. 41, pp. 77-85, 2010.

[32]H. Teherdoost, "Determining Sample Size, how to Calculate Survey Sample Size," International Journal of Economics and Management Systems, vol. 1, pp. 17-25, 2017.

[33] J. Hair, M. Sarstedt, C. Ringle, and J. Mena, "An Assessment of the use of Partial Least Squares Structural Equation Modelling in the Market Research," Journal of the Academy Marketing Science, vol. 40, pp. 414-433, 2019.

[34]H. Newkirk, and A. Lederer, "The Effectiveness of Strategic Information Systems Planning under Environmental Uncertainty," Information \& Management, vol. 43, pp. 481-501, 2006.

[35] P. Klarner, M. Sarstedt, M. Hoeck, and C. Ringle, "Adaptability, and client communication on the performance of management consulting teams," Long Range Planning, vol. 46, pp. 258-286, 2013.

\section{Creative Commons Attribution License 4.0 (Attribution 4.0 International, CC BY 4.0)}

This article is published under the terms of the Creative Commons Attribution License 4.0

https://creativecommons.org/licenses/by/4.0/deed.en_US 